Supporting Information

\title{
Uniform Deposition and Effective Confinement of Lithium in Three- Dimensional Interconnected Microchannels for Stable Lithium Metal Anodes
}

Jingjing Zhang a, Zhengkang Su ${ }^{a}$, Junhong Jin a , Shenglin Yang a, Aishui Yu ${ }^{b}$, , and Guang Li

$\mathrm{a}, *$

a State Key Laboratory for Modification of Chemical Fibers and Polymer Materials, Colle ge of Materials Science and Engineering, Donghua University, Shanghai 201620, China

b Department of Chemistry, Shanghai Key Laboratory of Molecular Catalysis and Innovative Materials, Institute of New Energy, Collaborative Innovation Center of Chemistry for Energy Materials, Laboratory of Advanced Materials, Fudan University, Shanghai 200438, China * E-mail: asyu@fudan.edu.cn (A.S.); lig@dhu.edu.cn (G.L.) 


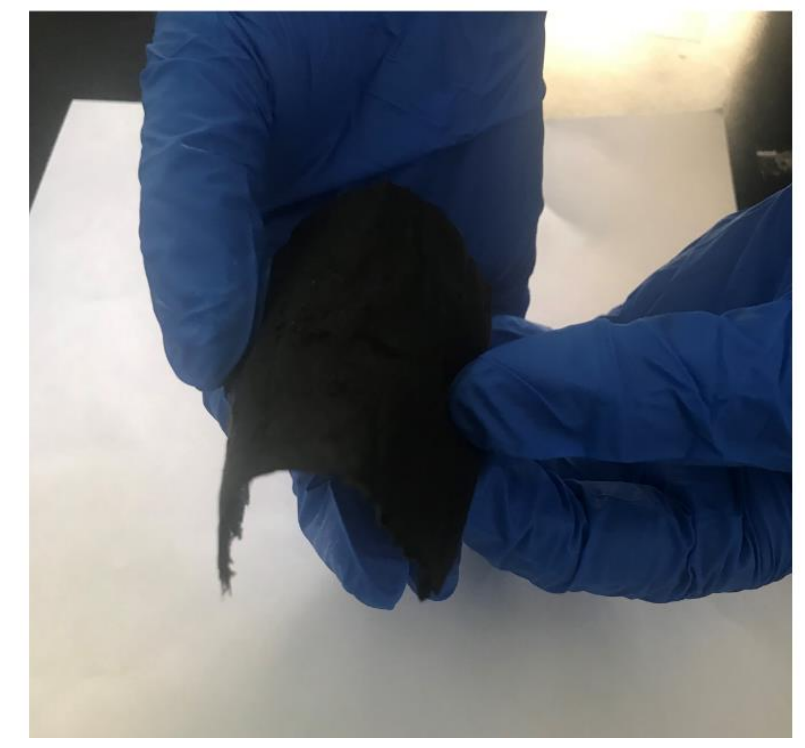

Figure S1. Picture of HTCNF-2 showing high flexibility. 


\section{HTCNF-1}

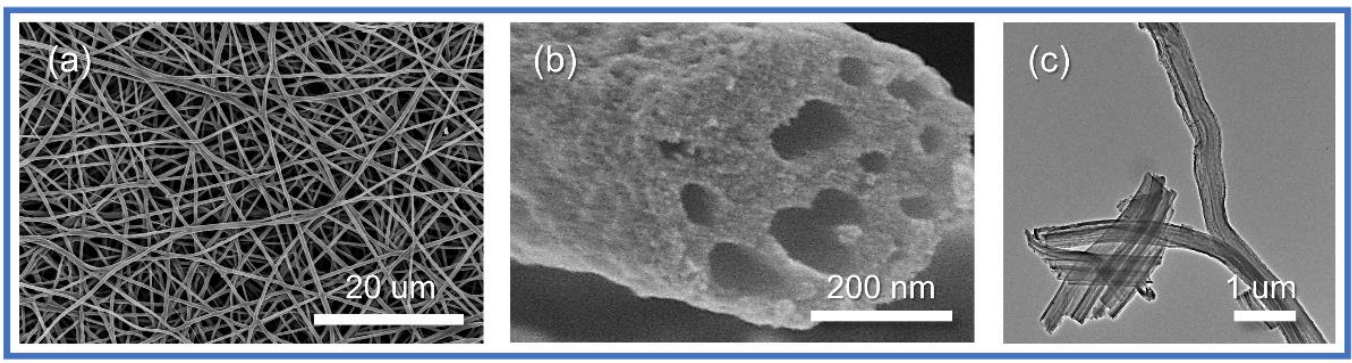

\section{HTCNF-3}

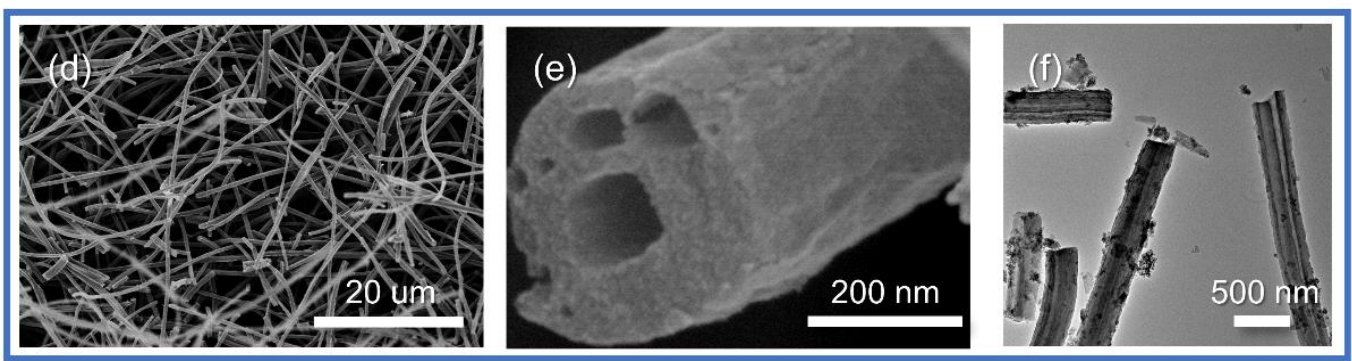

Figure S2. (a,b) SEM and (c) TEM images of HTCNF-1. (d,e) SEM and (f) TEM images of HTCNF-3. 


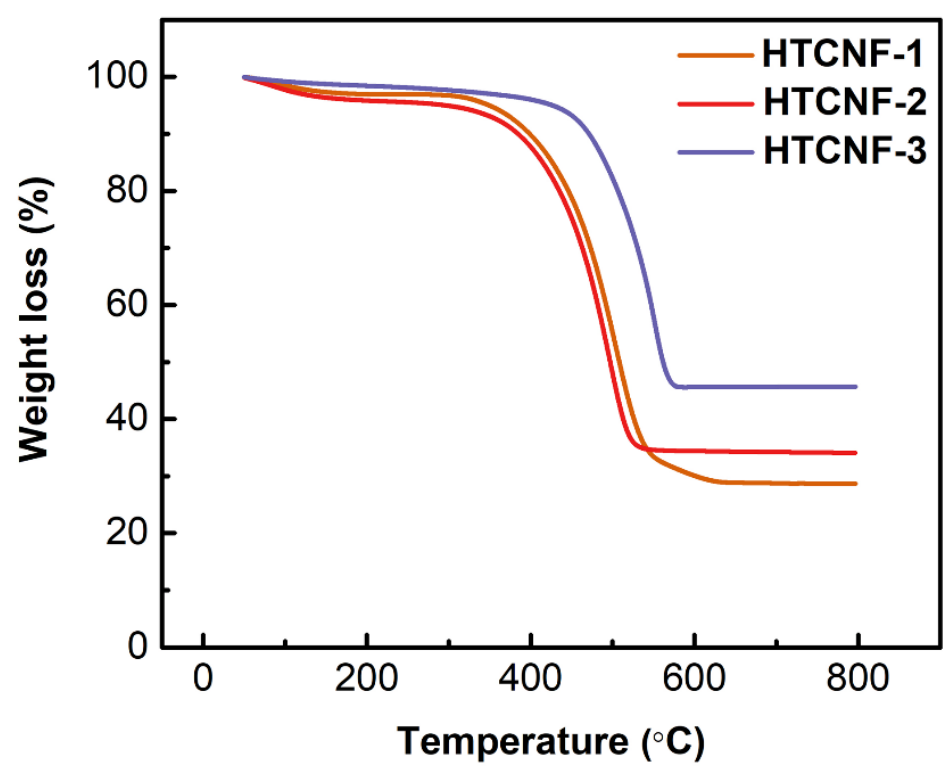

Figure S3. TG analys is of HTCNF-1, 2, 3 from $50{ }^{\circ} \mathrm{C}$ to $800{ }^{\circ} \mathrm{C}$ at a heating rate of $10{ }^{\circ} \mathrm{C} \mathrm{min}^{-1}$ in air. The weight loss below $200{ }^{\circ} \mathrm{C}$ is resulted bythe desorption of water vapor and evaporation of the gaseous content of the sample. The weight loss at $200-800{ }^{\circ} \mathrm{C}$ is attributed to the removal of the carbon. 


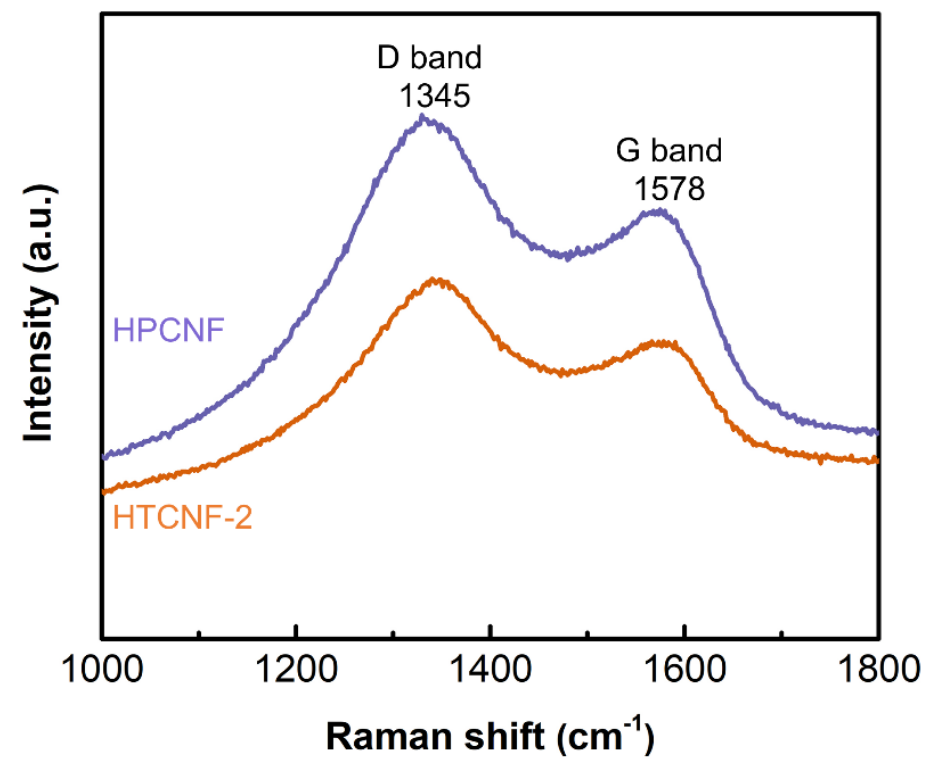

Figure S4. Raman spectrum of HPCNF and HTCNF-2 showing the D and G band. 

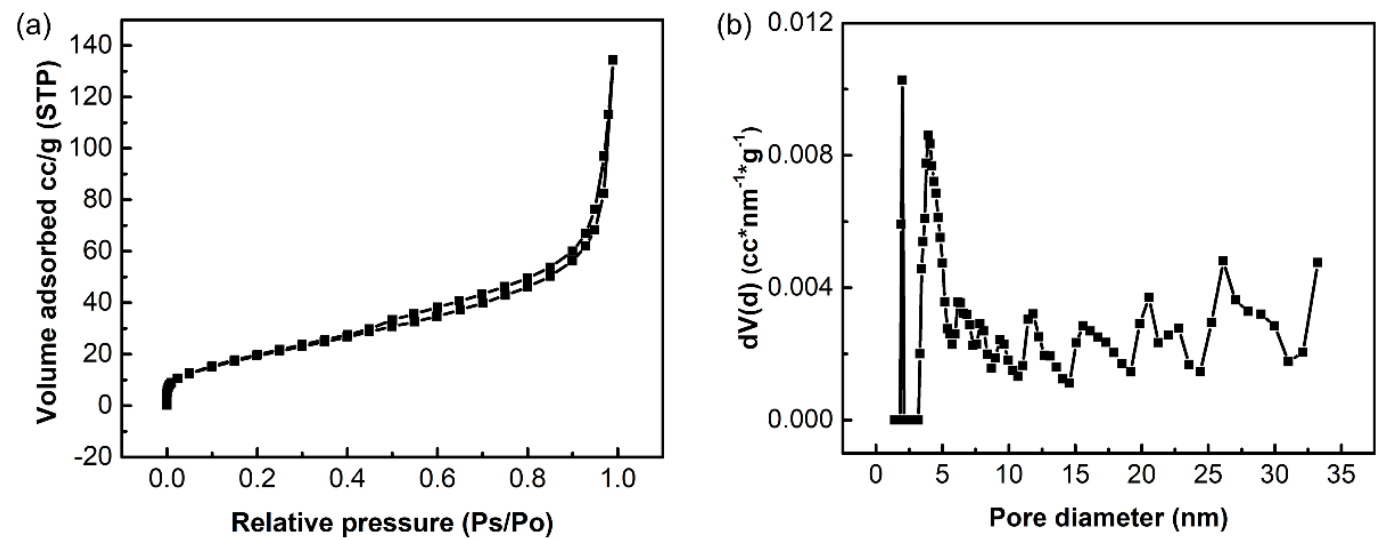

Figure S5. (a) $\mathrm{N}_{2}$ adsorption/desorption isotherms, and (b) the corresponding BJH pore size distribution of HTCNF-2. 

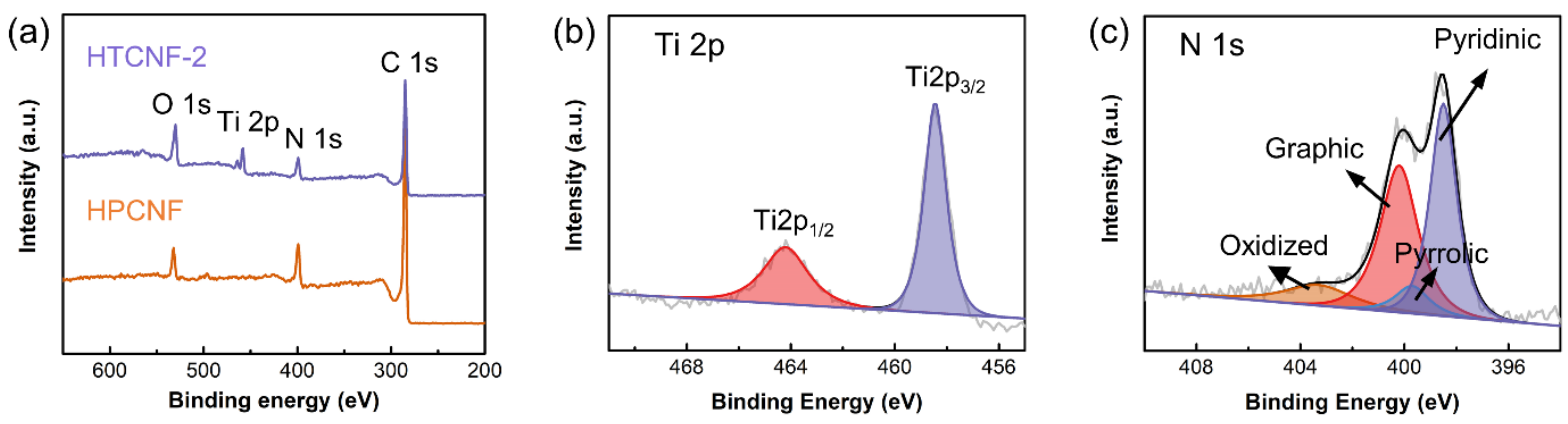

Figure S6. (a) XPS survey scans of HPCNF and HTCNF-2. High-resolution XPS spectra of HTCNF-2 showing the (b) Ti 2p and (c) $\mathrm{N}$ 1s regions. 

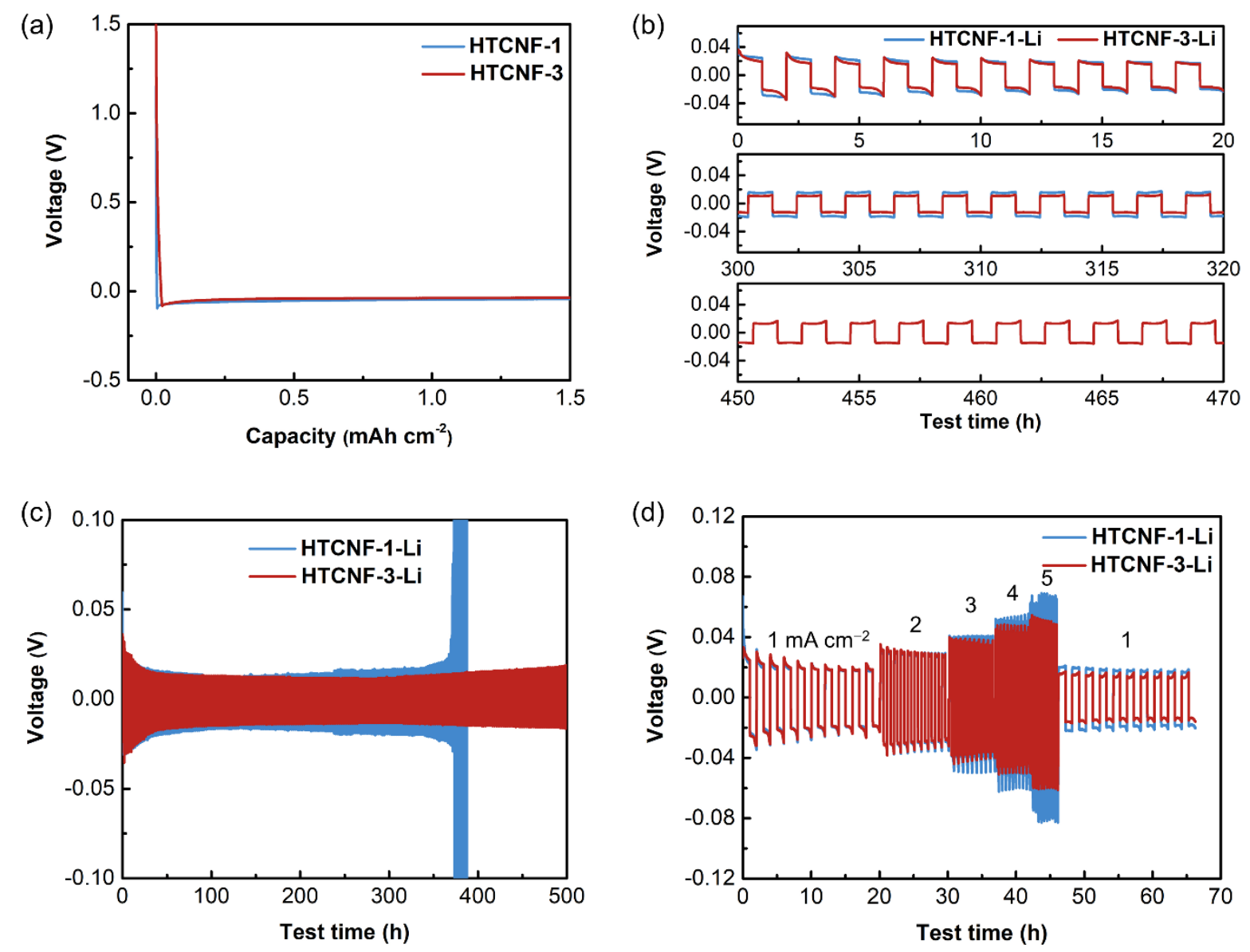

Figure S7. (a) Voltage capacity curves of Li plating on HTCNF-1 and HTCNF-3 at a current density of $1 \mathrm{~mA} \mathrm{~cm}-2$. (b,c) Voltage profiles of Li plating/stripping in the HTCNF-1-Li and HTCNF-3-Li symmetric cells at $1 \mathrm{~mA} \mathrm{~cm}^{-2}$ for $1 \mathrm{~mA} \mathrm{~h} \mathrm{~cm}{ }^{-2}$. (d) Rate performances of the HTCNF-1-Li and HTCNF-3-Li symmetric cells at the current density ranging from 1 to $5 \mathrm{~mA}$ $\mathrm{cm}^{-2}$. 

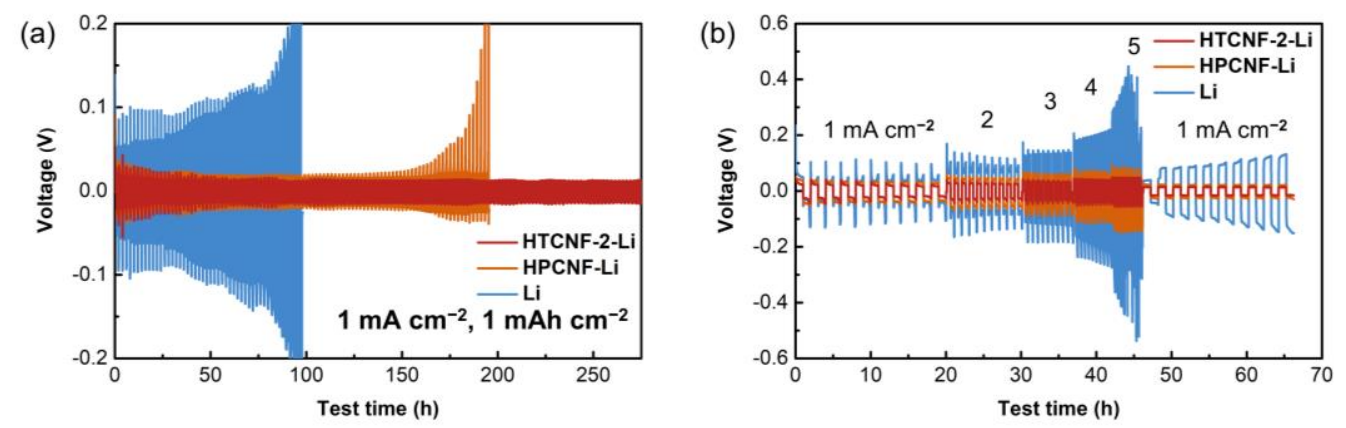

Figure S8. (a) Voltage profiles of Li plating/stripping for the HTCNF-2-Li, HPCNF-Li and Li symmetric cells at $1 \mathrm{~mA} \mathrm{~cm}{ }^{-2}$ for an areal capacity of $1 \mathrm{~mA} \mathrm{~h} \mathrm{~cm}{ }^{-2}$ with $1 \mathrm{M} \mathrm{LiPF}_{6}$ in EC/DEC $(1: 1, \mathrm{v} / \mathrm{v})$ electrolyte. We only show the cycling data of the first $275 \mathrm{~h}$ for comparison here, which demonstrates the versatility of the HTCNF-2 in hosting Li in carbonate electrolytes. (b) Rate performance of the HTCNF-2-Li, HPCNF-Li, and Li symmetric cells with the current density ranging from 1 to $5 \mathrm{~mA} \mathrm{~cm}{ }^{-2}$ with $1 \mathrm{M} \mathrm{LiPF}_{6}$ in $\mathrm{EC} / \mathrm{DEC}(1: 1, \mathrm{v} / \mathrm{v})$ electrolyte. 


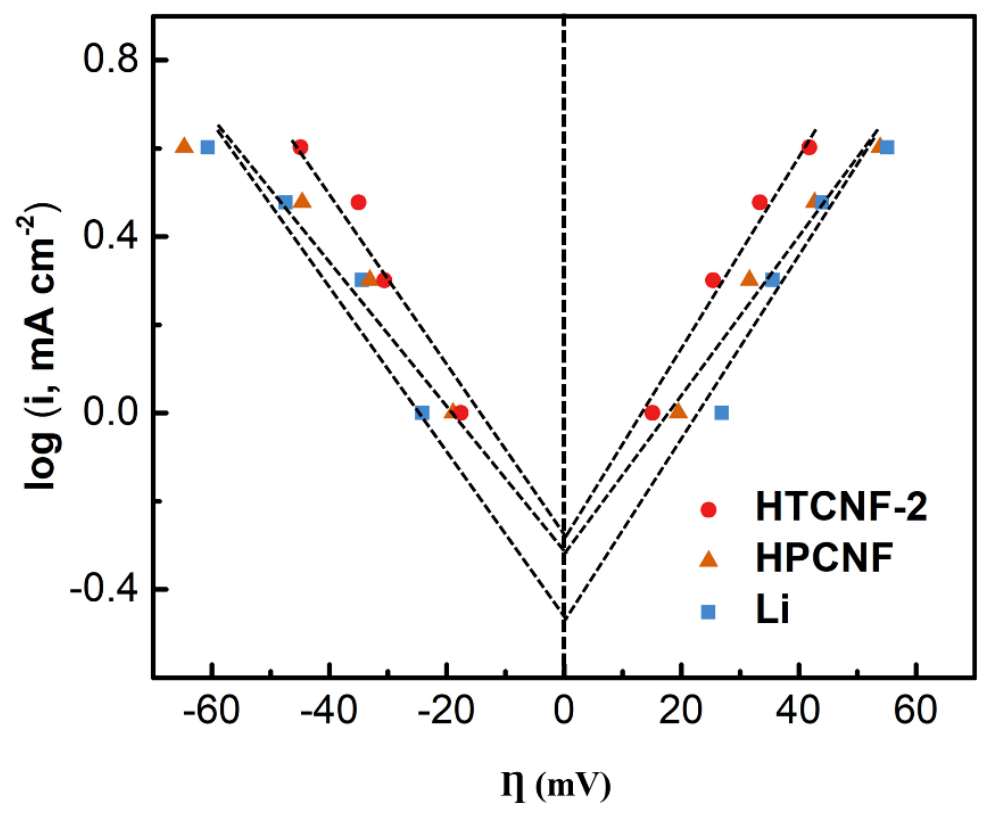

Figure S9. Plots of $\log (\mathrm{i})$ versus $\eta$ calculated based on the rate performances of the the investigated symmetric cells. 


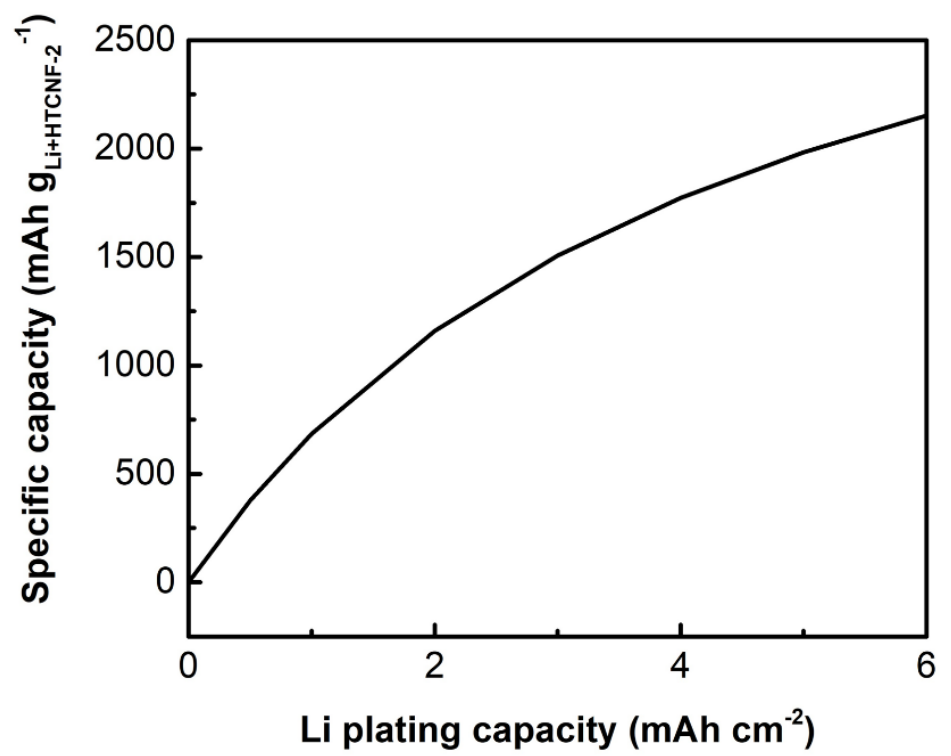

Figure S10. Effective specific capacity based on the total weight of the composite anode (HTCNF-2 + deposited Li metal) as a function of deposed Li amount. 


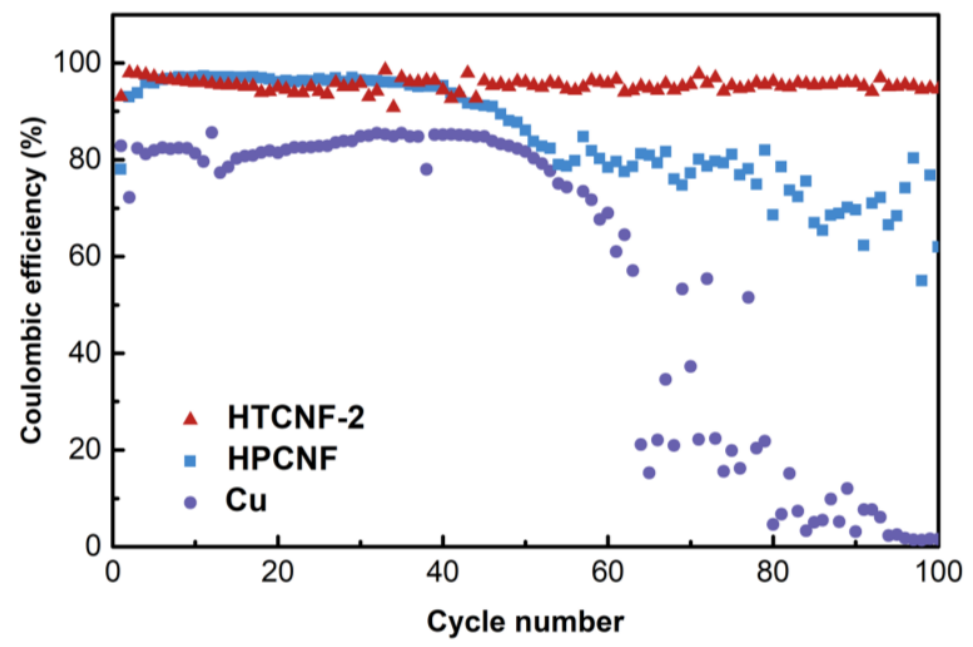

Figure S11. Coulombic efficiency of the HTCNF-2, HPCNF and $\mathrm{Cu}$ symmetric cells at $1 \mathrm{~mA}$ $\mathrm{cm}^{-2}$ with the capacity of $1 \mathrm{~mA} \mathrm{~h} \mathrm{~cm}{ }^{-2}$ using $1 \mathrm{M} \mathrm{LiPF}_{6}$ in EC/DEC (1:1, v/v) electrolyte. 

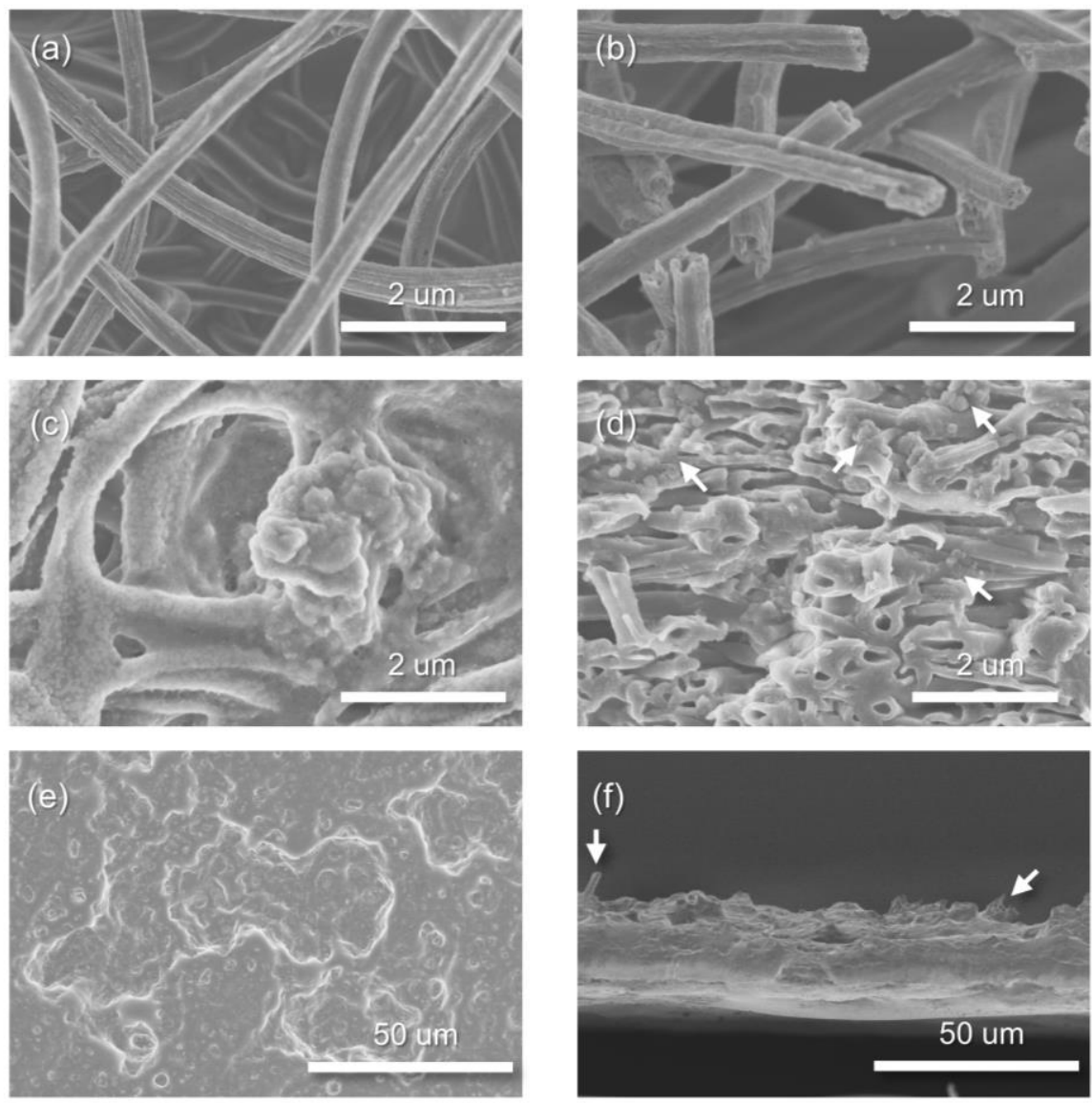

Figure S12. Top-view and cross-sectional SEM images of $(a, b)$ the HTCNF-2, (c,d) HPCNF and $(\mathrm{e}, \mathrm{f}) \mathrm{Cu}$ electrodes after 100 cycles of $\mathrm{CE}$ test. 

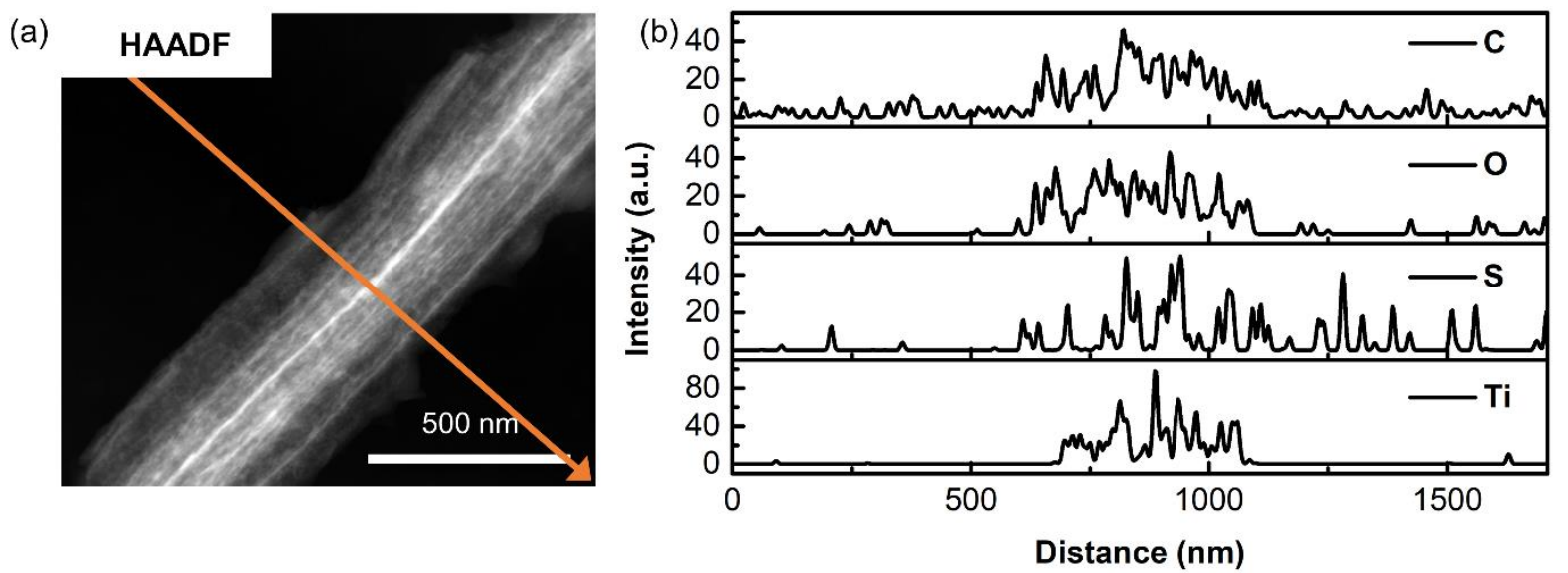

Figure S13. (a) HAADF-STEM image of HTCNF-2-Li electrode after 300 cycles of Li plating/stripping in symmetric cells. (b) Elemental distribution corresponding to the line scan highlighted by the orange arrow in (a). 


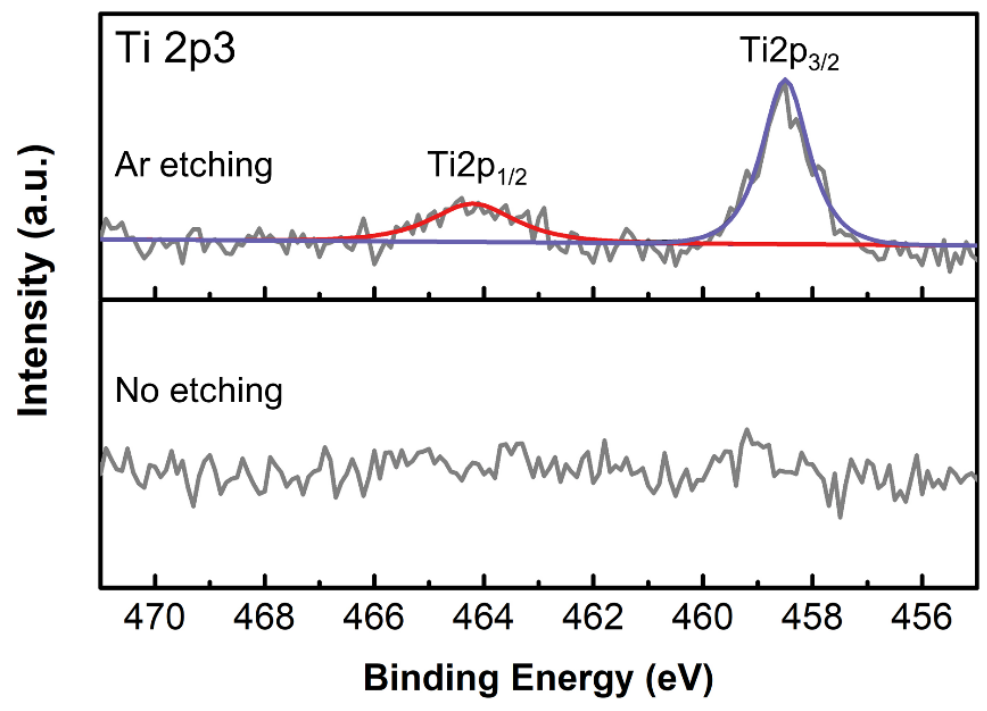

Figure S14. Ti 2p XPS spectra of HTCNF-2-Li electrode after 100 cycles of Li plating/stripping in symmetric cells with and without Ar etching. 

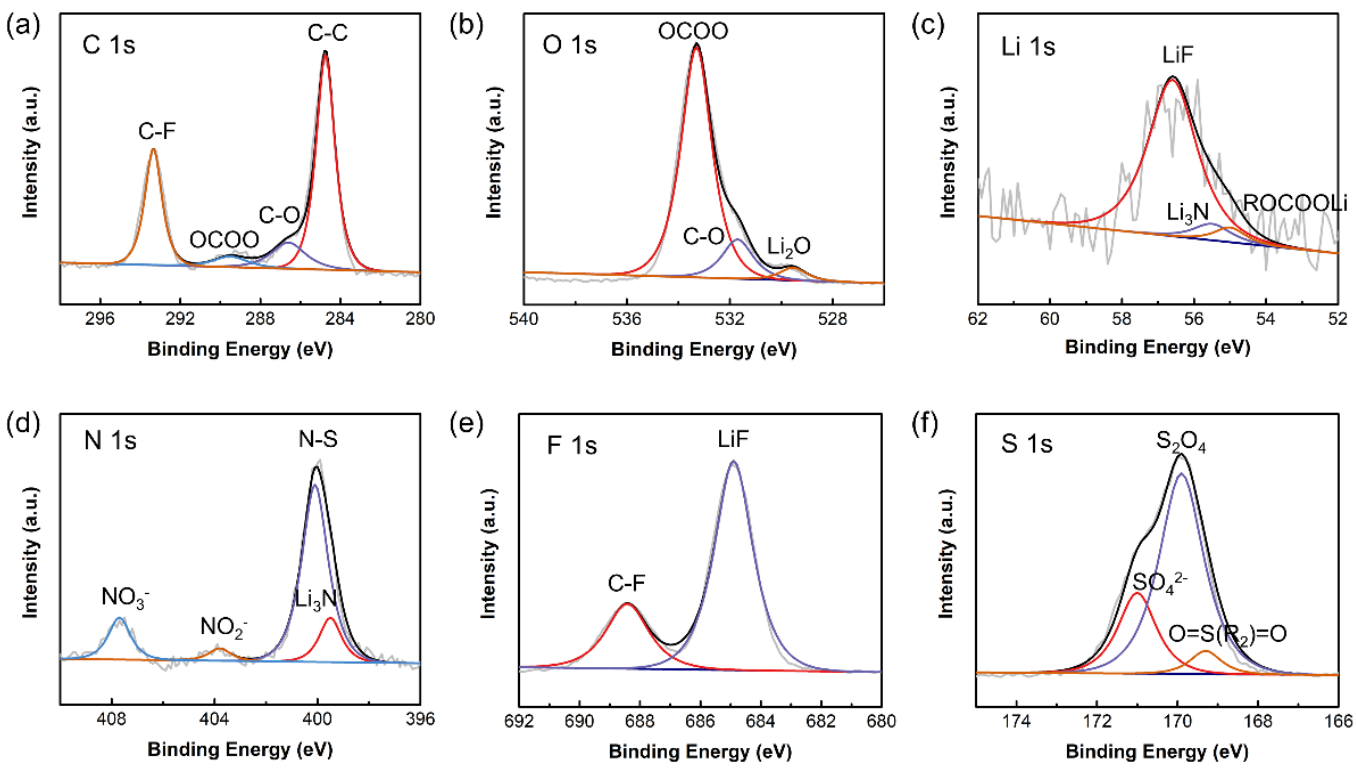

Figure S15. XPS characterization of the SEI formed on HTCNF-2-Li electrode after 100 cycles of Li plating/stripping in symmetric cells. 
(a)

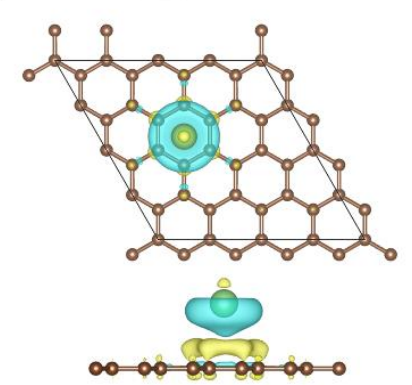

(d)

$$
\text { Gr-PrN-Li }
$$

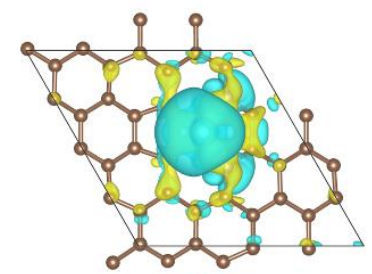

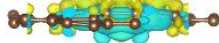

(b)

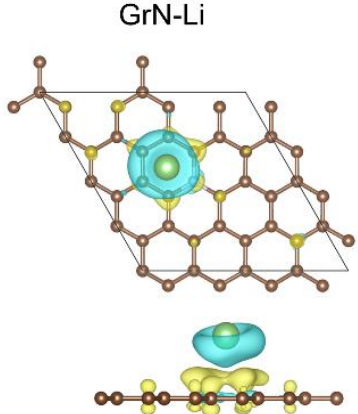

(e) (c) Gr-PyN-Li

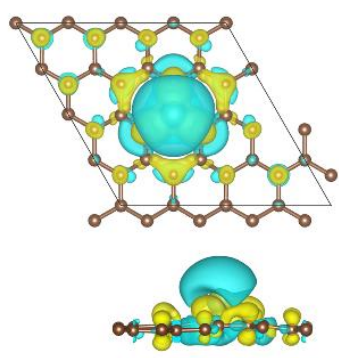

$\mathrm{TiO}_{2}-\mathrm{Li}$
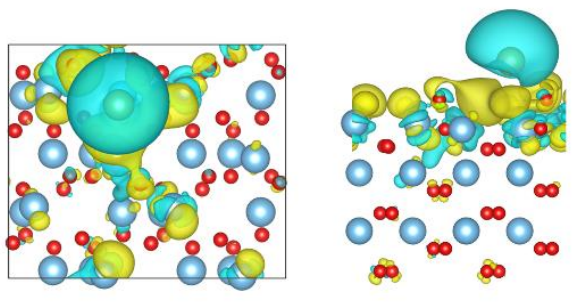

- C $\circ \mathrm{N} \circ \mathrm{O} \circ \mathrm{Ti} \circ \mathrm{Li}$

Figure S16. The differential charge density of a Li atom adsorbed on (a) C, (b) GrN, (c) PyN, (d) $\operatorname{PrN}$, and (e) $\mathrm{TiO}_{2}$. The yellow and green surfaces correspond to the charge accumulation and depletion regions, respectively (isovalue: 0.0009 ). 

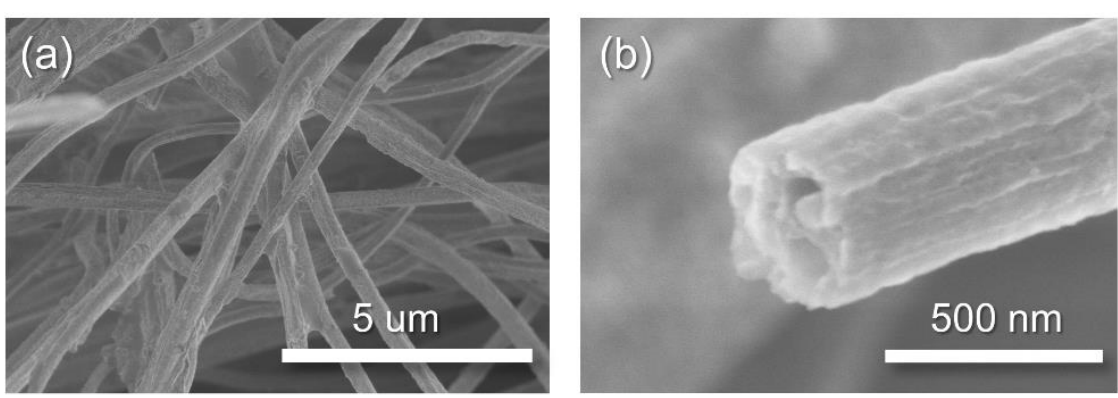

\section{mAh \\ $\mathrm{cm}^{-2}$}
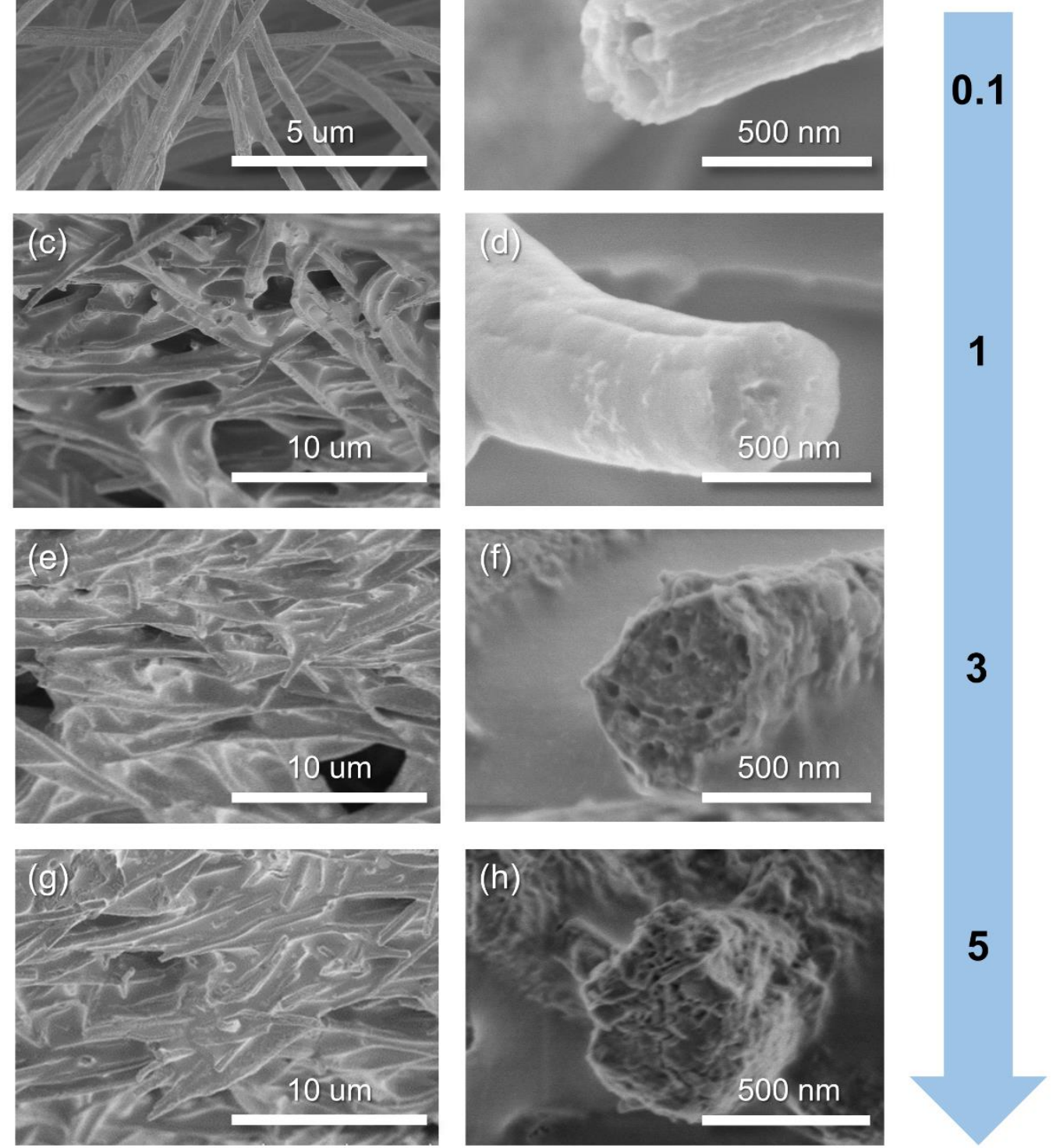

Figure S17. Cross-sectional SEM images of HTCNF-2 frameworks upon Li metal deposition with the capacity of $(\mathrm{a}, \mathrm{b}) 0.1,(\mathrm{c}, \mathrm{d}) 1,(\mathrm{e}, \mathrm{f}) 3$, and $(\mathrm{g}, \mathrm{h}) 5 \mathrm{~mA} \mathrm{~h} \mathrm{~cm} \mathrm{~cm}^{-2}$. 

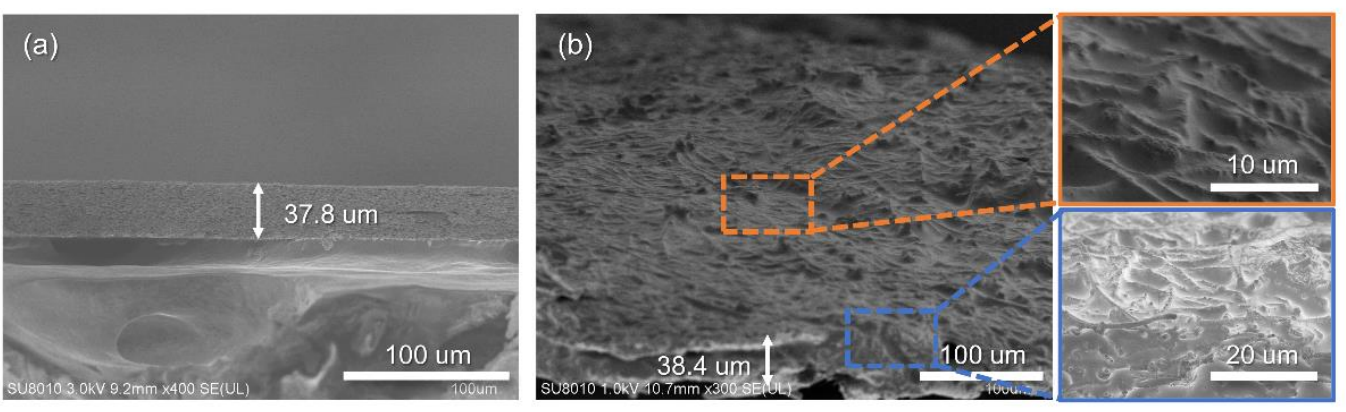

Figure S18. Cross-sectional SEM images of (a) pristine HTCNF-2 and (b) HTCNF-2 upon Li

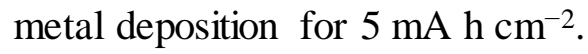



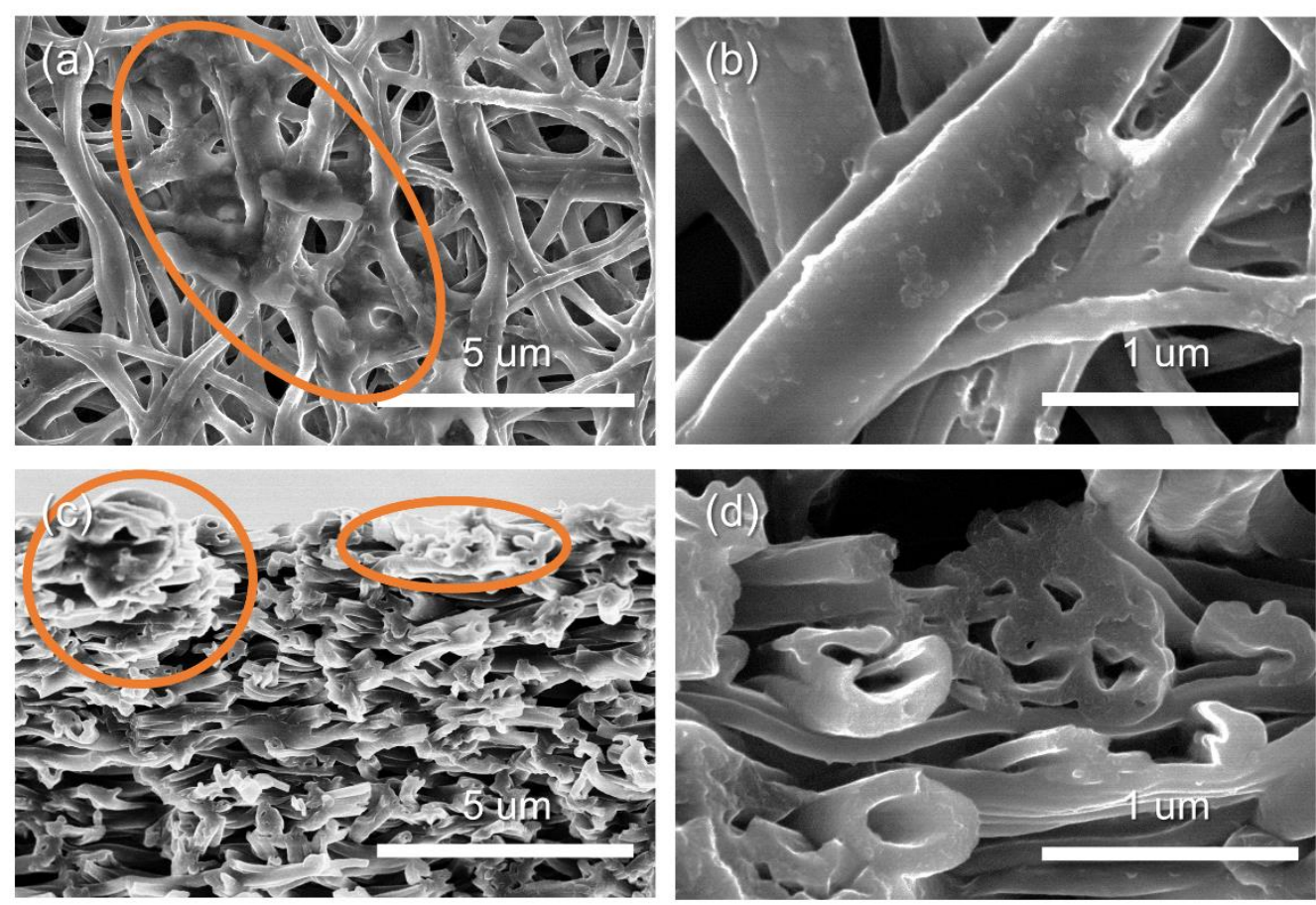

Figure S19. (a,b) Top-view and (c,d) cross-sectional SEM images of HPCNF upon Li metal deposition for $5 \mathrm{~mA} \mathrm{~h} \mathrm{~cm}$, where nonuniform Li deposits are highlighted using orange circles. 

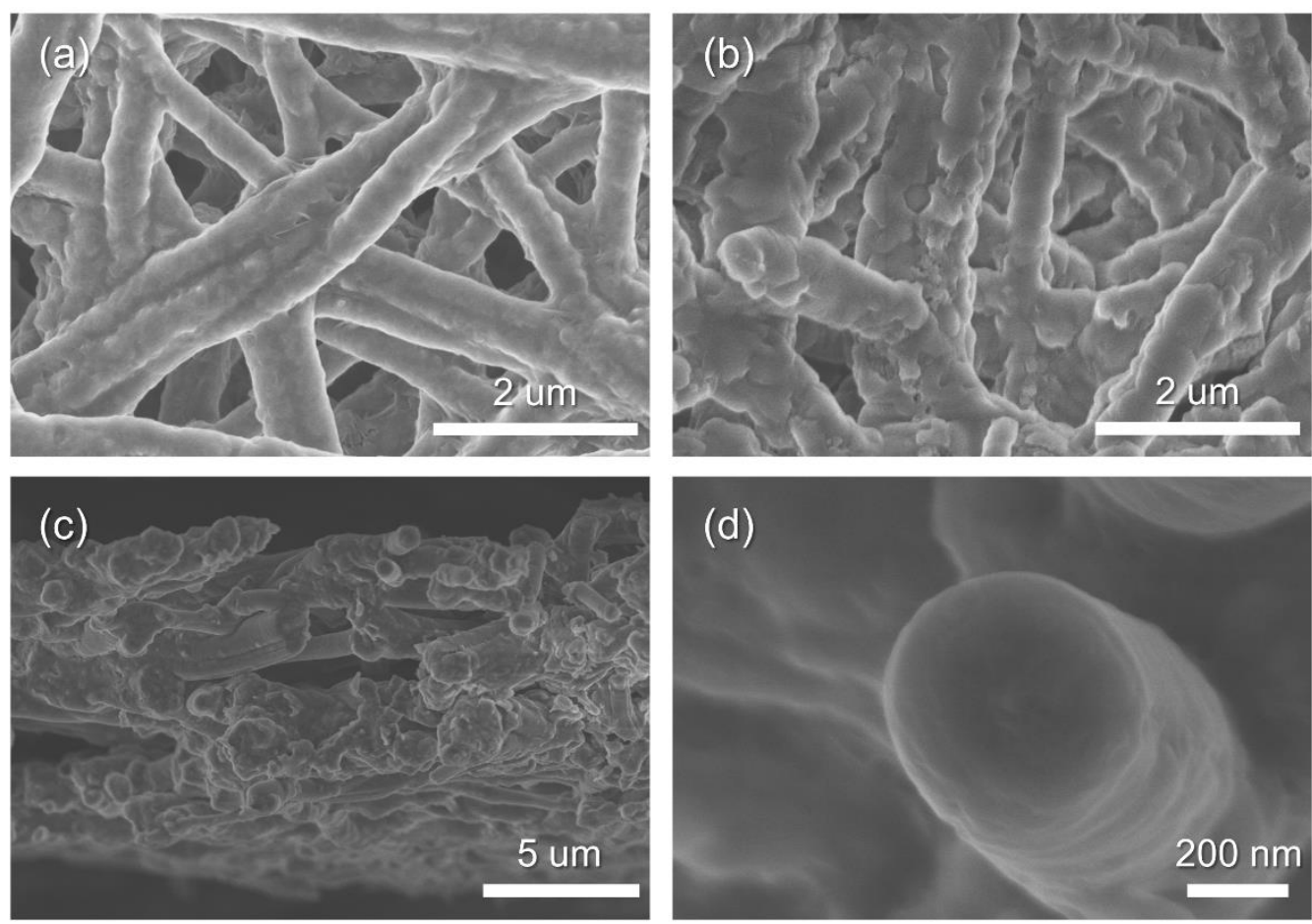

Figure S20. (a) Top-view SEM image of HTCNF-2 frameworks upon melt-infusion of Li $\left(400{ }^{\circ} \mathrm{C}\right.$ ) for 5 min. (b) Top-view and (c,d) cross-sectional SEM images of HTCNF-2 frameworks upon melt-infusion of $\operatorname{Li}\left(400^{\circ} \mathrm{C}\right)$ for $30 \mathrm{~min}$. 
(a)

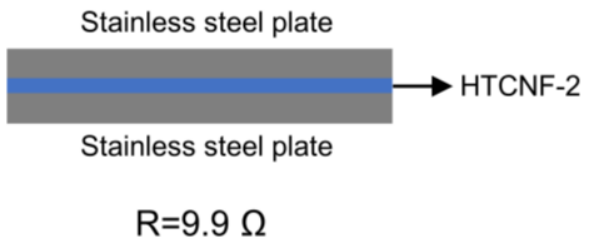

(b)

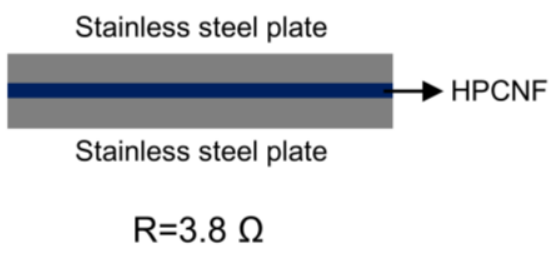

Figure S21. Electrical resistivity measurements of (a) HTCNF-2 and (b) HPCNF. The calculated resistivity corresponds to the overall value of the entire fixture including the stainless steel discs. This shows the electrical conductivity is decreased upon introducing the $\mathrm{TiO}_{2}$ nanoparticles. 


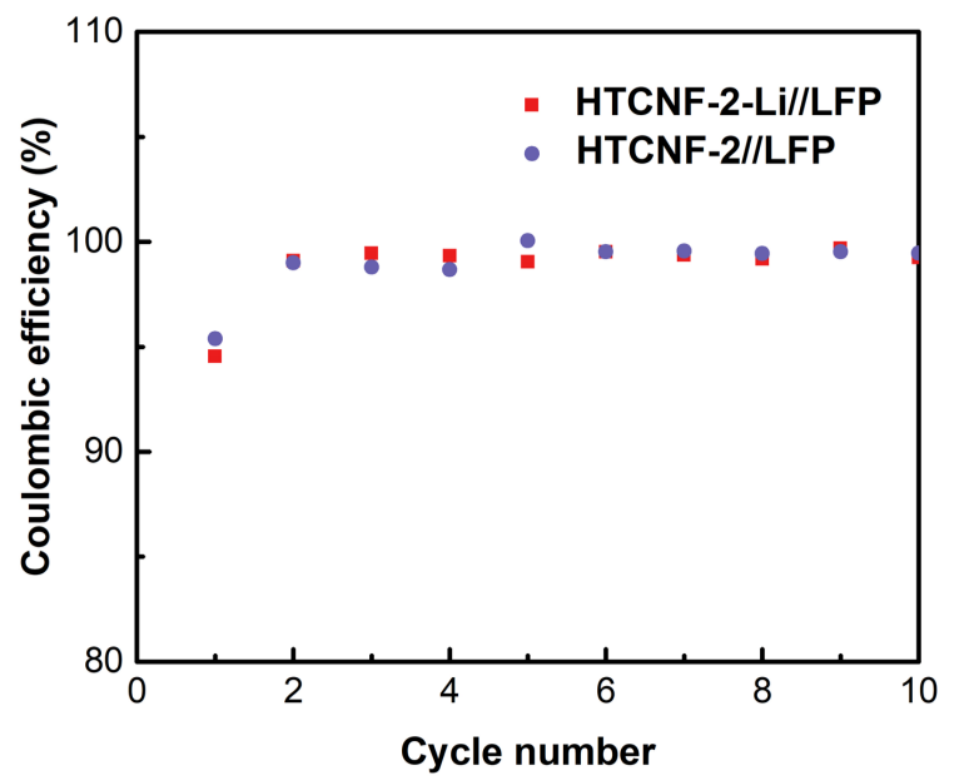

Figure S22. Comparison of Coulombic efficienc y of the HTCNF-2-Li//LFP and HTCNF-2//LFP full cells at the current density of $0.5 \mathrm{C}$. 
Table S1. Comparative summary of performance of symmetric cells and full cells in this work and other reported studies on $3 \mathrm{D} \mathrm{Li}$ hosts

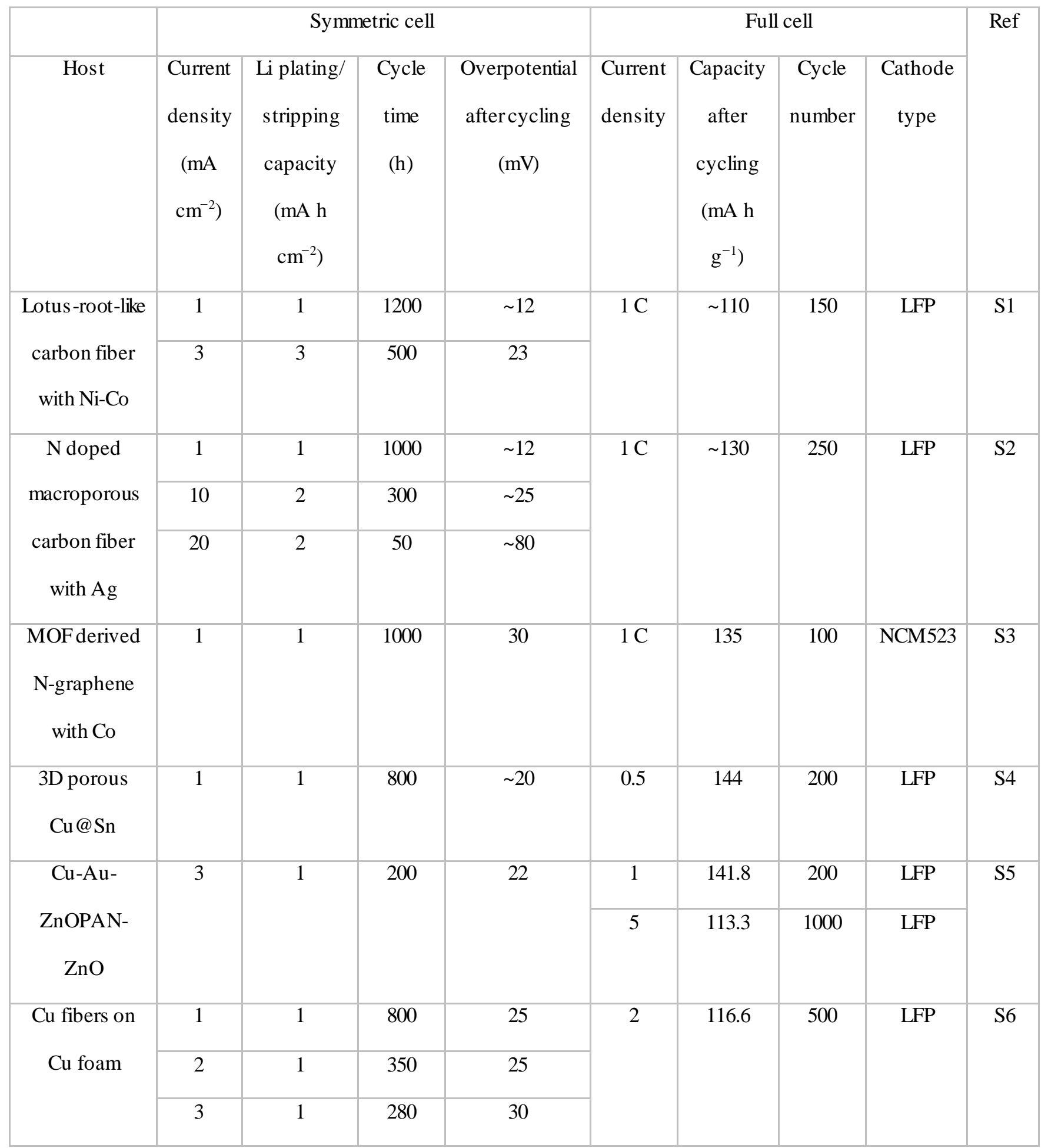




\begin{tabular}{|c|c|c|c|c|c|c|c|c|c|}
\hline $\begin{array}{c}\text { PDA@3DCu } \\
\text { scaffold }\end{array}$ & 0.5 & 0.5 & 1000 & $\sim 24$ & $0.5 \mathrm{C}$ & 101.4 & 100 & LFP & S7 \\
\hline $\begin{array}{c}3 \mathrm{D} \mathrm{Zn}- \\
\mathrm{Cu}_{0.7} \mathrm{Sn}_{0.3}-\mathrm{Cu} \\
\text { foam }\end{array}$ & 2.5 & 1.5 & 1200 & 10 & $5 \mathrm{C}$ & 100.9 & 1600 & LFP & S8 \\
\hline $\begin{array}{c}\mathrm{g}-\mathrm{C}_{3} \mathrm{~N}_{4} @ \mathrm{Ni} \\
\text { foam }\end{array}$ & $\begin{array}{l}1 \\
2\end{array}$ & $\begin{array}{l}1 \\
1\end{array}$ & $\begin{array}{l}900 \\
500\end{array}$ & $\begin{array}{l}<15 \\
\sim 20\end{array}$ & $1 \mathrm{C}$ & $\sim 90$ & 200 & $\mathrm{LiCoO}_{2}$ & S9 \\
\hline $\begin{array}{c}\text { Carbon fiber } \\
\text { mat } \\
\text { with TiN }\end{array}$ & $\begin{array}{l}1 \\
4\end{array}$ & $\begin{array}{l}1 \\
1\end{array}$ & $\begin{array}{l}600 \\
100\end{array}$ & $\begin{array}{l}30 \\
250\end{array}$ & $1 \mathrm{C}$ & 122.4 & 250 & LFP & S10 \\
\hline HTCNF-2-Li & $\begin{array}{l}1 \\
3\end{array}$ & 1 & $\begin{array}{l}1300 \\
250\end{array}$ & $\begin{array}{l}6 \\
54\end{array}$ & $0.5 \mathrm{C}$ & 134 & 400 & LFP & $\begin{array}{l}\text { Our } \\
\text { work }\end{array}$ \\
\hline
\end{tabular}

\section{REFERENCES}

(S1) Chen, C.; Guan, J.; Li, N. W.; Lu, Y.; Luan, D. Y.; Zhang, C. H.; Cheng, G.; Yu, L.; Lou, X. W. Lotus-Root-Like Carbon Fibers Embedded with Ni-Co Nanoparticles for DendriteFree Lithium Metal Anodes. Adv. Mater. 2021, 33, 2100608.

(S2) Fang, Y. J.; Zhang, S. L.; Wu, Z. P.; Luan, D. Y.; Wen, X.; Lou, X. W. A Highly Stable Lithium Metal Anode Enabled by Ag Nanoparticle - Embedded Nitrogen-Doped Carbon Macroporous Fibers. Sci. Adv. 2021, 7, eabg3626.

(S3) Wang, T. S.; Liu, X. B.; Zhao, X. D.; He, P. G.; Nan, C. W.; Fan, L. Z. Regulating Uniform Li Plating/Stripping via Dual-Conductive Metal-Organic Frameworks for HighRate Lithium Metal Batteries. Adv. Funct. Mater. 2020,30, 2000786.

(S4) Luo, Z.; Liu, C.; Tian, Y.; Zhang, Y.; Jiang, Y. L.; Hu, J. H.; Hou, H. S.; Zou, G. Q.; Ji, X. 
B. Dendrite-Free Lithium Metal Anode with Lithiophilic Interphase from Hierarchical Frameworks by Tuned Nucleation. Energy Storage Mater. 2020, 27, 124-132.

(S5) Zheng, H. F.; Zhang, Q. F.; Chen, Q. L.; Xu, W. J.; Xie, Q. S.; Cai, Y. X.; Ma, Y. T.; Qiao, Z. S.; Luo, Q.; Lin, J.; Wang, L. S.; Qu, B. H.; Sa, B. S.; Peng, D. L. 3D LithiophilicLithiophobic-Lithiophilic Dual-Gradient Porous Ske leton for Highly Stable Lithium Metal Anode. J. Mater. Chem. A 2020, 8, 313-322.

(S6) Zhao, Y.; Hao, S. G.; Su, L.; Ma, Z. P.; Shao, G. J. Hierarchical Cu Fibers Induced Li Uniform Nucleation for Dendrite-Free Lithium Metal Anode. Chem. Eng. J. 2020, 392, 123691.

(S7) Jiang, J. M.; Pan, Z. H.; Kou, Z. K.; Nie, P.; Chen, C. L.; Li, Z. W.; Li, S. P.; Zhu, Q.; Dou, H.; Zhang, X. G.; Wang, J. Lithiophilic Polymer Interphase Anchored on LaserPunched 3D Holey $\mathrm{Cu}$ Matrix Enables Uniform Lithium Nucleation Leading to SuperStable Lithium Metal Anodes. Energy Storage Mater. 2020, 29, 84-91.

(S8) Cheng, Y. F.; Ke, X.; Chen, Y. M.; Huang, X. Y.; Shi, Z. C.; Guo, Z. P. LithiophobicLithiophilic Composite Architecture through Co-Deposition Technology toward HighPerformance Lithium Metal Batteries. Nano Energy 2019, 63, 103854.

(S9) Lu, Z. Y.; Liang, Q. H.; Wang, B.; Tao, Y.; Zhao, Y. F.; Lv, W.; Liu, D. H.; Zhang, C.; Weng, Z.; Liang, J. C.; Li, H.; Yang, Q. H. Graphitic Carbon Nitride Induced MicroElectric Field for Dendrite-Free Lithium Metal Anodes. Adv. Energy Mater. 2019, 9, 1803186.

(S10) Lin, K.; Qin, X. Y.; Liu, M.; Xu, X. F.; Liang, G. M.; Wu, J. X.; Kang, F. Y.; Chen, G. H.; Li, B. H. Ultrafine Titanium Nitride Sheath Decorated Carbon Nanofiber Network Enabling Stable Lithium Metal Anodes. Adv. Funct. Mater. 2019, 29, 1903229. 
